\title{
Evaluation of the Impact of Maternal Training on Knowledge of Danger Signs in Sick Newborns and Health Seeking Behaviors Among Mothers in Enugu, South-east Nigeria- a Pre-and-post Interventional Study
}

\section{Uchenna Ekwochi}

Enugu State University of Science and Technology College of Medicine

\section{Ikenna Kingsley Ndu}

Enugu State University of Science and Technology College of Medicine

Obinna C Nduagubam

Enugu State University of Science and Technology College of Medicine

Onyinye $\mathrm{H}$ Chime

Enugu State University of Science and Technology College of Medicine Ogechukwu F Amadi

Enugu State University of Science and Technology College of Medicine Chizoma Eneh

Enugu State University of Science and Technology College of Medicine Isaac N Asinobi

Enugu State University of Science and Technology College of Medicine Donatus Ignatius Chidiebere Osuorah ( $\square$ chidi.osuorah@hotmail.com )

Medical Research Council The Gambia: Medical Research Council Unit The Gambia at the London School of Hygiene and Tropical Medicine https://orcid.org/0000-0002-1956-5955

\section{Research article}

Keywords: interventional study, World health Organization, Participant's knowledge, newborn care

Posted Date: December 6th, 2021

DOI: https://doi.org/10.21203/rs.3.rs-1132848/v1

License: (c) (i) This work is licensed under a Creative Commons Attribution 4.0 International License. Read Full License 


\section{Abstract}

Background: During the early weeks of life, the signs/symptoms of serious illness can be subtle, thus careful watching is crucial. The World health Organization has recognized nine "danger sign" which are closely associated with morbidity and mortality when not recognized early and given adequate care. This project was undertaken to assess mothers' knowledge of these danger signs and health seeking behavior before and after training on newborn danger signs.

Methodology: This community-based interventional study was carried amongst women in two rural communities of Enugu State. Participant's knowledge of danger signs and care seeking behaviors were obtained using an interviewer administered questionnaire before and after training on the danger signs newborns using videos from the Integrated Management of Childhood IIInesses (IMCI). Pre- and posttraining data were collated for analysis and comparison using SPSS version 20.

Results: A total of 197 women were enrolled for the study. Among the socio-demographic indices examined, only the number of newborns nursed in the past significantly determined knowledge of danger signs in the sick newborn ( $P=0.032)$. Prior to the training, $47 \%$ of respondents could not recount offhand any danger sign compared to $1.5 \%$ after the training $(P=0.001)$. Knowledge of up to 3 danger signs significantly increased after the training $(P=0.001)$ and participants who admitted seeking medical help within 24 hours of noticing any danger signs in newborn also significantly increased, $(P=0.043)$.

Conclusion: Our study documented a strong impact of training of mothers on their knowledge of danger signs in the sick newborns and on their healthcare seeking behavior. Therefore, training and retraining of mothers and/or care givers could help improve newborn care and reduce overall infant mortality

\section{Introduction}

Neonatal mortality is of global importance as 2.4 million deaths were recorded among children within the first month of life in $2019 .{ }^{1}$ Approximately, 6,700 neonates die daily, amounting to $47 \%$ of under-five mortality globally. ${ }^{1}$ Although the world has made substantial progress in child survival with neonatal deaths declining from 5.0 million in 1990 to 2.4 million in 2019, sub-Saharan Africa had the highest mortality rate at 27 deaths per 1,000 live births. ${ }^{1}$ In Nigeria, 270,000 newborns died from preventable and treatable causes in 2019, giving a mortality rate of 36/1000 live births, the highest in Africa and the second highest globally. ${ }^{1,2}$

Mortality and morbidity risks are higher in newborn compared to other age groups in childhood due to inherent immature immune status. Hence, a newborn can die within minutes if prompt recognition, diagnosis and treatment are not initiated. ${ }^{3}$ Additionally, signs of sickness are often subtle hence easily missed out by untrained mothers in the household. These factors lead to increased newborn death at home or at best, late presentation to hospital with high risk of death. The World health Organization has documented the "danger sign" in the sick newborn which are closely associated with increased risk of 
disability or death when not recognized early and given adequate cares. ${ }^{1}$ The danger sign are; poor feeding since birth or stopped feeding, convulsion, respiratory rate of 60 or more (fast breathing), severe chest indrawing (difficulty in breathing), temperature of more 37.5 degree centigrade or more (fever), temperature of 35.5 degree centigrade or less (hypothermia), only moves when stimulated or not even when stimulated (weakness or lethargy), yellow soles (signs of local infection). ${ }^{4}$

Majority of the newborn deaths are related to late recognition of neonatal danger signs, delays in seeking appropriate care and subsequent late intervention at the time of presentation to the hospital. ${ }^{5,6,7}$ Babies having danger signs, born to mothers residing in rural areas are at a higher risk of death than those residing in urban areas. ${ }^{8}$ Data on Maternal and Newborn health disparities in Nigeria reveals that neonatal mortality rate is higher in the rural areas with an urban-to-rural ratio of $0.8 .{ }^{9}$ Findings from a study in some rural communities in Enugu State recorded poor knowledge level (0-30\%) of danger signs of illness in the sick newborn. ${ }^{10}$ In the study, adequate health seeking behaviour by mothers was significantly determined by knowledge of at-least one danger sign in their sick newborn; as mothers who had knowledge of three or more WHO recognized danger signs compared with those who had two or less were less likely to delay at household level in seeking appropriate care for their sick newborn. ${ }^{10}$ Additionally, the study identified other perceived and experienced non WHO recognized danger signs among the study population. The authors thereafter recommended that a formal training of these women will enhance their capacity to recognize the danger signs of illness in the newborn early enough and institute healthy interventions that will enhance survival of their newborns.

On the strength of the foregoing, this project therefore aimed at equipping mothers with skills to identify danger signs in the sick newborn and educate them on the appropriate health seeking behavior for the survival of their sick newborn. Thereafter, we sought to assess mothers' knowledge and the maternal characteristic that determined adequate knowledge of these danger signs and secondarily, the impact of this training on their knowledge of danger signs and health care seeking behaviors.

\section{Methodology}

\section{Study area}

This community-based interventional study was conducted in Enugu state, the host state of Enugu State University of Science and Technology. The study was conducted over a seven (7) months period as a follow-up study in two communities of the 17 communities where poor knowledge of maternal danger signs was previously documented in our earlier study. ${ }^{10}$ The communities are Ndiuno-Uwani Akpugo in Nkanu West Local Government Area (LGA) of Enugu state and Nomeh in Nkanu East LGA. The inhabitants of these communities are predominantly cassava and yam farmers at subsistence level. There are about 400 women in Ndiuno-Uwani Akpugo and approximately 500 women in Nomeh communities. Nomeh is about 30 kilometers from Amagunze the Nkanu East LGA Headquarters, while Ndiuno-Uwani Akpugo is about 3 kilometers from Agbani, the Nkanu West LGA headquarters. 


\section{The Pre-Training Phase}

All women aged 18-60 years within each study community who had nursed at least one newborn were invited to the community square on a convenient day as determined by their community leaders. On the day of training, the women were consecutively enrolled after signing or thumb-printing an informed consent form. Their knowledge of danger signs, healthcare seeking behavior and socio-demographic profiles were obtained using a structured interviewer administered questionnaire. They were asked to recount extempore the danger signs in the sick newborn, the immediate action they take when such signs are observed in their newborns and how early they would normally decide to take their sick newborns to a health care facility. Their sociodemographic indices and responses were documented in the questionnaires and categorized as follows:

1. Age was recategorized into $\leq 29$ years; $30-40$ years and $>40$ years.

2. Socioeconomic class was assessed using Oyedeji's socioeconomic indices and categorized into upper, middle, and low socioeconomic classes. ${ }^{11}$

3. Number of newborns nursed $1-3 ; 4-6$ and $\geq 7$.

\section{The Training Phase}

After completing the questionnaires, a plenary session was conveyed for the participants during which the Integrated Management of Childhood IIInesses (IMCl) video on the danger signs in the sick newborn was projected on a screen and important actions in the video interpreted in the Igno, the native language of all the participants. ${ }^{7}$ During the training is was repeatedly emphasized that the most appropriate action to take on noticing any of the danger signs is to immediately take the newborn to a health facility.

\section{Post-Training Phase}

Three months after the training, a return visit was made to the communities to assess the impact of the training on the participant's knowledge of danger signs in the sick newborns and health seeking behavior. This was conducted by administering to each participant, a similar questionnaire completed in the pretraining phase. Quality control checks were done on site after each field activity by researchers. Pre- and post-training responses for each participant were collated for analysis and comparison using SPSS version 20.

\section{Results}

\section{Characteristics of study participants}

This study was carried out in 2 rural communities in Enugu state namely Nomeh and Ndiuno Uwani Akpugo. All study participants were women, 120 participants were recruited from Nomeh and the remaining 77 from Ndiuno Uwani Akpugo. Of the 197 respondents, 30\% were 29 years or younger, 43\%) were between $30-40$ years while $27 \%$ were over the age of $40 y e a r s$ of age. Most respondents (46\%) had 
nursed at least 3 newborns through infancy while $54 \%$ had nursed more than 3 newborns. Respondents from the middle socioeconomic class made up $69 \%$ of the study population with other from the low (28\%) and high (6\%) socioeconomic class respectively. Other demographic of study respondents is shown in Table 1. 
Table 1

Summary Statistics of Mother/Caregivers Enrolled in Study

\begin{tabular}{|c|c|c|c|}
\hline Study parameter & Variables & Frequency & Percentage \\
\hline & & (n) & (\%) \\
\hline Community members surveyed & Ndiuno uwani Akpugo & 77 & 39.0 \\
\hline$(N=197)$ & Nomeh & 120 & 61.0 \\
\hline Age of respondents & $\leq 29$ years & 59 & 30.0 \\
\hline \multirow[t]{2}{*}{$(N=197)$} & $30-40$ years & 85 & 43.0 \\
\hline & $>40$ years & 53 & 27.0 \\
\hline Number of newborns nursed & $1-3$ & 90 & 46.0 \\
\hline \multirow[t]{2}{*}{$(N=197)$} & $4-6$ & 82 & 42.0 \\
\hline & $\geq 7$ & 25 & 12.0 \\
\hline Socio-economic class & Low & 55 & 28.0 \\
\hline \multirow[t]{2}{*}{$(N=197)$} & Middle & 136 & 69.0 \\
\hline & High & 6 & 3.0 \\
\hline Mother's education & None & 27 & 14.0 \\
\hline \multirow[t]{3}{*}{$(N=197)$} & Completed primary & 92 & 47.0 \\
\hline & Completed secondary & 38 & 19.0 \\
\hline & Post-secondary & 40 & 20.0 \\
\hline Father's education & None & 28 & 16.0 \\
\hline \multirow[t]{3}{*}{$(N=180)$} & Completed primary & 68 & 38.0 \\
\hline & Completed secondary & 28 & 16.0 \\
\hline & Post-secondary & 56 & 30.0 \\
\hline Mother's occupation & Unemployed & 90 & 46.0 \\
\hline \multirow[t]{3}{*}{$(N=197)$} & Unskilled & 74 & 38.0 \\
\hline & Semi-skilled & 25 & 12.0 \\
\hline & Skilled & 8 & 4.0 \\
\hline Father's occupation & Unemployed & 59 & 33.0 \\
\hline \multirow[t]{2}{*}{$(N=179)$} & Unskilled & 50 & 28.0 \\
\hline & Semi-skilled & 50 & 28.0 \\
\hline
\end{tabular}




\section{$\begin{array}{llll}\text { Study parameter } & \text { Variables } & \text { Frequency } & \text { Percentage }\end{array}$

\begin{tabular}{rrr|}
\hline Skilled & 20 & 11.0 \\
\hline
\end{tabular} \\ Sociodemographic determinants of knowledge of danger signs among respondents}

Table 2 shows the adjusted regression analysis of sociodemographic determinants of knowledge of danger signs in caregiver. It is noted that respondents $30-40$ years and those over 40 years were 0.78 and 0.96 less likely to lack knowledge of any danger sign compared to caregiver 29 years and younger OR 0.78 (95\% $\mathrm{Cl} 0.39-1.59) ; \mathrm{P}=0.497$ and $\mathrm{OR} 0.96$ (95\% $\mathrm{Cl} 0.39-2.37) ; \mathrm{P}=0.935$ respectively. This however did not attain statistical significance. It was also noted that respondents that have nursed 4-6 newborns, OR 0.81 (95\% Cl $0.61-2.29)$ and those who have nursed $\geq 7$ OR 0.32 (95\% Cl $0.11-0.90)$ less likely to lack knowledge of danger signs. In other words, mother that have nursed 4-6 and those who have nursed $\geq 7$ newborns were approximately 1.2 and 3 times more likely to have knowledge of danger signs in children. Similarly, respondents with completed primary [OR $0.77(95 \% \mathrm{Cl} 0.22-2.71) ; P=0.688$ ], those with completed secondary [OR $0.84(95 \% \mathrm{Cl} 0.35-2.02) ; P=0.699$ ] and post-secondary education [OR 0.77 ( $95 \% \mathrm{Cl} 0.30-1.99) ; P=0.597$ ] were less likely to lack knowledge of at least 1 danger signs compared to those with no formal education. Like age, none attained statistical significance. Finally, respondents who were in unskilled employment were slightly less likely to lack knowledge of at least 1 danger sign compared to those who are unemployed OR 0.93 (95\% Cl OR 0.47 - 1.88) while those in semi-skilled OR 1.37 (95\% Cl 0.47 - 4.02) and skilled OR 1.44 (95\% Cl 0.30 - 6.79) employment were more likely to lack knowledge of danger signs compared to respondents that are unemployed 
Table 2

Sociodemographic determinants of knowledge of danger signs among respondents

\begin{tabular}{|c|c|c|c|c|c|c|}
\hline \multirow[t]{2}{*}{ Danger signs } & \multirow[t]{2}{*}{ Variables } & \multicolumn{2}{|c|}{$\begin{array}{l}\text { Knowledge of danger } \\
\text { signs } n(\%) \dagger^{1}\end{array}$} & \multirow{2}{*}{$\begin{array}{l}\square^{2} \\
P \dagger^{1}\end{array}$} & \multicolumn{2}{|c|}{$\begin{array}{l}\text { Logistic regression } \\
\text { analysis }\end{array}$} \\
\hline & & No & Yes & & OR $95 \% \mathrm{Cl}$ & $P+^{2}$ \\
\hline Age of respondents & $\leq 29$ years & $25(27)$ & $34(33)$ & 0.943 & 1 & - \\
\hline \multirow[t]{2}{*}{$(N=197)$} & $30-40$ years & $43(46)$ & $42(40)$ & 0.624 & $\begin{array}{l}0.78(0.39 \\
-1.59)\end{array}$ & 0.497 \\
\hline & $>40$ years & $25(27)$ & $28(27)$ & & $\begin{array}{l}0.96(0.39 \\
-2.37)\end{array}$ & 0.935 \\
\hline $\begin{array}{l}\text { Number of } \\
\text { newborns nursed }\end{array}$ & $1-3$ & $40(43)$ & $50(48)$ & 7.115 & 1 & - \\
\hline \multirow[t]{2}{*}{$(N=197)$} & $4-6$ & $35(38)$ & $47(45)$ & 0.029 & $\begin{array}{l}0.81(0.61 \\
-2.29)\end{array}$ & 0.622 \\
\hline & $\geq 7$ & $18(19)$ & $7(7)$ & & $\begin{array}{l}0.32(0.11 \\
-0.90)\end{array}$ & 0.032 \\
\hline $\begin{array}{l}\text { Socio-economic } \\
\text { class }\end{array}$ & Low & $25(28)$ & $28(23)$ & 0.020 & 1 & - \\
\hline \multirow[t]{2}{*}{$(N=197)$} & Middle & $64(69)$ & $72(69)$ & 0.990 & $\begin{array}{l}0.80(0.38 \\
-1.71)\end{array}$ & 0.684 \\
\hline & High & $4(3)$ & $4(2)$ & & $\begin{array}{l}1.24(0.41 \\
-2.20)\end{array}$ & 0.789 \\
\hline Mother's education & None & $13(14)$ & $74(14)$ & 1.070 & 1 & - \\
\hline \multirow[t]{3}{*}{$(N=197)$} & $\begin{array}{l}\text { Completed } \\
\text { primary }\end{array}$ & $45(49)$ & $47(45)$ & 0.784 & $\begin{array}{l}0.77(0.22 \\
-2.71)\end{array}$ & 0.688 \\
\hline & $\begin{array}{l}\text { Completed } \\
\text { secondary }\end{array}$ & $19(20)$ & $19(18)$ & & $\begin{array}{l}0.84(0.35 \\
-2.02)\end{array}$ & 0.699 \\
\hline & Post-secondary & $16(17)$ & $24(23)$ & & $\begin{array}{l}0.77(0.30 \\
-1.99)\end{array}$ & 0.597 \\
\hline $\begin{array}{l}\text { Mother's } \\
\text { occupation }\end{array}$ & Unemployed & $46(46)$ & $47(45)$ & 1.067 & 1 & - \\
\hline \multirow[t]{2}{*}{$(N=197)$} & Unskilled & $37(40)$ & $37(36)$ & 0.785 & $\begin{array}{l}0.93(0.47 \\
-1.88)\end{array}$ & 0.845 \\
\hline & Semi-skilled & $10(11)$ & $15(14)$ & & $\begin{array}{l}1.37(0.47 \\
-4.02)\end{array}$ & 0.571 \\
\hline
\end{tabular}

${ }^{1}$ Knowlegde of at least 1 danger signs; $t^{2}$ Bold value of $P$ is statistically significant 


\begin{tabular}{|c|c|c|c|c|c|c|}
\hline \multirow[t]{2}{*}{ Danger signs } & \multirow{2}{*}{$\begin{array}{l}\text { Variables } \\
\text { Skilled }\end{array}$} & \multicolumn{2}{|c|}{$\begin{array}{l}\text { Knowledge of danger } \\
\text { signs } n(\%) t^{1}\end{array}$} & \multirow[t]{2}{*}{$\square^{2}$} & \multicolumn{2}{|c|}{$\begin{array}{l}\text { Logistic regression } \\
\text { analysis }\end{array}$} \\
\hline & & $3(3)$ & $5(5)$ & & $\begin{array}{l}1.44(0.30 \\
-6.79)\end{array}$ & 0.647 \\
\hline
\end{tabular}

\section{Respondents' knowledge of dangers sign pre and post educational intervention}

Table 3 shows number of danger sign known by respondents before and after training in WHO recognized danger signs. Prior to the training, $47 \%$ of respondents could not recount any danger sign which reduced to $1.5 \%$ after the training $(P=0.001)$. Similarly, prior to the training $2.5 \%, 9,6 \%$ and $16.2 \%$ were able to mention 1,2 and 3 dangers signs compared to $12.7 \%(P=0.04), 35.5 \%(P=0.001)$ and $32.5 \%(P=0.001)$ respectively after the training. There was no significant difference of knowledge for knowledge of 4 or more danger signs before and after the training, 29 (14.7\%) vs $22(11.2 \%) ; P=0.356$ for 4 danger sign; 9 (4.6\%) vs. 7 (3.6\%) $P=0.624$ for 5 danger signs, 6 (3.0\%) vs. 11 (5.6\%); $P=0.235$ for 6 danger signs, 3 (1.5\%) vs $1(0.5 \%) ; P=0.622$ for 7 danger signs, 1 (0.5\%) vs $0(0 \%) ; P=0.998$ for 8 danger signs. In summary, respondents with at least 1 knowledge of danger sign increased from 104 (52.8\%) before to $194(98.5 \%)$ after the training intervention $(P=0.001)$. In addition, respondents that admitted they would seek medical help when danger signs are noticed in the newborn increased from 94 (47.7\%) preintervention to $179(90.9 \%)$ post intervention $(P=0.001)$. Finally, of respondents that indicated they would seek medical intervention, significantly less would present within 24 hours of noticing the danger signs after the intervention, 88 (49.1\%) compared before the intervention $58(61.7 \%) ; P=0.043$. Tables 4 and 5 shows knowledge and action regarding individual danger signs. 
Table 3

Pre and post intervention assessment danger signs parameters and appropriate action taken

\begin{tabular}{|c|c|c|c|}
\hline \multirow[t]{2}{*}{ Parameter } & \multicolumn{3}{|l|}{ Intervention } \\
\hline & Pre & Post & P-valuet \\
\hline \multicolumn{4}{|c|}{ Total number of danger sign known by respondents $(N=197)$} \\
\hline None & $93(47 \%)$ & $3(1.5 \%)$ & 0.001 \\
\hline 1 & $5(2.5 \%)$ & $25(12.7 \%)$ & 0.004 \\
\hline 2 & $19(9.6 \%)$ & $64(32.5 \%)$ & 0.001 \\
\hline 3 & $32(16.2 \%)$ & $64(32.5 \%)$ & 0.033 \\
\hline 4 & $29(14.7 \%)$ & $22(11.2 \%)$ & 0.356 \\
\hline 5 & $9(4.6 \%)$ & $7(3.6 \%)$ & 0.624 \\
\hline 6 & $6(3.0 \%)$ & $11(5.6 \%)$ & 0.235 \\
\hline 7 & $3(1.5 \%)$ & $1(0.5 \%)$ & 0.622 \\
\hline 8 & $1(0.5 \%)$ & $0(0 \%)$ & 0.998 \\
\hline 9 & $0(0 \%)$ & $0(0 \%)$ & - \\
\hline At least 1 & $104(52.8 \%)$ & $194(98.5 \%)$ & 0.001 \\
\hline \multicolumn{4}{|c|}{ Action to be taken if and/or when danger sign observed in newborn ( $N=197$, } \\
\hline \multicolumn{4}{|l|}{ Would seek healthcare } \\
\hline No & $103(52.3 \%)$ & $18(9.1 \%)$ & 0.001 \\
\hline Yes & $94(47.7 \%)$ & $179(90.9 \%)$ & \\
\hline \multicolumn{4}{|c|}{ Time from observing danger sign to seeking healthcare } \\
\hline Time to hospital presentation & $(N=94)$ & $(N=179)$ & \\
\hline$<24$ hours & $58(61.7 \%)$ & $88(49.1 \%)$ & 0.043 \\
\hline$\geq 24$ hours & $36(38.3 \%)$ & $91(50.1 \%)$ & \\
\hline
\end{tabular}


Table 4

Knowledge of Dangers sign among Participants enrolled in the study

\begin{tabular}{|c|c|c|c|c|c|c|}
\hline \multirow[t]{2}{*}{ Danger signs } & \multirow[t]{2}{*}{ Knowledge } & \multicolumn{2}{|c|}{ Pre-intervention } & \multicolumn{2}{|c|}{ Post-intervention } & \multirow[t]{2}{*}{ P-valuet } \\
\hline & & $\mathrm{n}$ & $\%$ & $\mathrm{n}$ & $\%$ & \\
\hline Refusal/Stop feeding & No & 146 & 74 & 115 & 58 & 0.010 \\
\hline$(N=197)$ & Yes & 51 & 26 & 82 & 42 & \\
\hline Convulsion & No & 153 & 78 & 160 & 81 & 0.382 \\
\hline$(N=197)$ & Yes & 44 & 22 & 37 & 19 & \\
\hline Fast breathing & No & 170 & 86 & 180 & 91 & 0.110 \\
\hline$(N=197)$ & Yes & 27 & 41 & 17 & 9 & \\
\hline Fever & No & 107 & 54 & 20 & 10 & 0.001 \\
\hline$(N=197)$ & Yes & 90 & 56 & 177 & 90 & \\
\hline Hypothermia & No & 157 & 80 & 140 & 71 & 0.047 \\
\hline$(N=197)$ & Yes & 40 & 20 & 57 & 29 & \\
\hline Weakness/Lethargy & No & 152 & 77 & 88 & 45 & 0.001 \\
\hline$(N=197)$ & Yes & 45 & 23 & 109 & 55 & \\
\hline Jaundice & No & 183 & 93 & 161 & 82 & 0.009 \\
\hline$(N=197)$ & Yes & 14 & 7 & 36 & 18 & \\
\hline Difficulty in breathing & No & 192 & 75 & 187 & 95 & 0.001 \\
\hline$(N=197)$ & Yes & 49 & 25 & 10 & 5 & \\
\hline Local infectionst & No & 148 & 75 & 99 & 50 & 0.001 \\
\hline$(N=197)$ & Yes & 49 & 25 & 98 & 50 & \\
\hline
\end{tabular}


Table 5

Actions taken by Parent/caregiver when and/or if danger sign noticed in infant

\begin{tabular}{|c|c|c|c|c|c|c|}
\hline \multirow[t]{2}{*}{ Danger signs } & \multirow{2}{*}{$\begin{array}{l}\text { Sought } \\
\text { Healthcare }\end{array}$} & \multicolumn{2}{|c|}{ Pre-intervention } & \multicolumn{2}{|c|}{ Post-intervention } & \multirow[t]{2}{*}{ P-valuet } \\
\hline & & $\mathbf{n}$ & $\%$ & $\mathrm{n}$ & $\%$ & \\
\hline Refusal/Stop feeding & No & 166 & 84 & 130 & 66 & 0.001 \\
\hline$(N=197)$ & Yes & 31 & 16 & 67 & 34 & \\
\hline Convulsion & No & 183 & 93 & 134 & 68 & 0.001 \\
\hline$(N=197)$ & Yes & 14 & 7 & 63 & 32 & \\
\hline Fast breathing & No & 159 & 81 & 166 & 54 & 0.002 \\
\hline$(N=197)$ & Yes & 38 & 19 & 91 & 46 & \\
\hline Fever & No & 183 & 93 & 145 & 74 & 0.001 \\
\hline$(N=197)$ & Yes & 14 & 7 & 52 & 26 & \\
\hline Hypothermia & No & 176 & 90 & 147 & 75 & 0.001 \\
\hline$(N=197)$ & Yes & 20 & 10 & 50 & 25 & \\
\hline Weakness/Lethargy & No & 162 & 82 & 135 & 68 & 0.002 \\
\hline$(N=197)$ & Yes & 35 & 18 & 62 & 32 & \\
\hline Jaundice & No & 176 & 89 & 138 & 70 & 0.001 \\
\hline$(N=197)$ & Yes & 21 & 11 & 59 & 30 & \\
\hline Difficulty in breathing & No & 163 & 83 & 116 & 59 & 0.001 \\
\hline$(N=197)$ & Yes & 34 & 17 & 80 & 41 & \\
\hline Local infectionst & No & 178 & 90 & 131 & 67 & 0.001 \\
\hline$(N=197)$ & Yes & 19 & 10 & 65 & 33 & \\
\hline
\end{tabular}

\section{Discussion}

This interventional study assessed knowledge of danger signs in newborns among women mainly of the reproductive age group, low and middle socioeconomic class, and those who had also achieved some level of formal education.

Even though statistical significance was not attained probably due sample size, our study showed that increasing maternal educational attainment was associated with better knowledge of danger sign in 
newborn. Maternal education has been shown to improve child health and earlier preventive care initiatives. ${ }^{12}$ Maternal education is also a signal of trainability because it enables appreciation of the benefits that can be gained from complying with recommended health practices and can improve their uptake. $^{13,14}$ Thus, the subjects were expected to be in good standing to maximally benefit from whatever knowledge or skills provided by the training. This is consistent with the findings of similar studies, ${ }^{14,15}$ and it has been suggested that these mothers with less education were more likely to rely on assistance from relatives with similar educational status than mothers with higher levels of education ${ }^{14}$ On the other hand, a cross-sectional study in a Neonatal Intensive Care Unit (NICU), North Central Ethiopia, documented that Secondary and above levels of education were among the factors reported as significant determinants of knowledge of neonatal danger signs among postnatal mothers. ${ }^{16}$

Our study also revealed that the number of newborns previously nursed by the respondents stood out as a significant determinant of their knowledge of danger signs in the sick newborn. Similarly, a crosssectional survey of women's knowledge and reported practices on maternal and child health in rural Sierra Leone revealed that the number of children significantly influenced health knowledge scores. ${ }^{17}$ This finding is consistent with the age-long adage that "experience is the best teacher". It stands to reason that they have gained such knowledge from caring for their newborns over the years. Some caregivers, possibly, got the correct information after counseling following the death of their newborn due to their failure to detect the signs early enough. It is also noteworthy that the other maternal socio-demographic variables had been shown not to be significant determinants of knowledge of danger signs in the first phase of this study in the same communities about six (6) years ago. ${ }^{10}$

Our study documented a strong influence of training in enhancing the knowledge of danger signs in sick newborns among mothers. Of the nine (9) WHO recognized danger signs in the sick newborn (refusal to feed/ stop feeding, convulsion, fast breathing, fever, hypothermia, weakness/lethargy, jaundice, difficulty in breathing, and local infections) ${ }^{4}$ there was a significant improvement in the knowledge of seven namely refusal to feed/ stop feeding, fever, hypothermia, weakness/lethargy, jaundice, difficulty in breathing and local infections in the post- training phase. A similar study on the impact of training on knowledge and care-seeking behavior of caregivers has documented that trained traditional birth attendants (TBAs) were more knowledgeable about danger signs during pregnancy and childbirth and were more likely to refer women with complications to a health facility, compared to untrained TBAs. ${ }^{18}$ There is a saying that "Training gives everyone a great understanding of their responsibilities and the knowledge and skills they need to do that job. This will enhance their confidence which can also improve their overall performance" ${ }^{19}$ It is the authors' view that our participants formal educational background has primed them to comprehend the content of the training.

Early recognition of these signs will enhance care and survival of the newborn because many newborn deaths are related to late recognition of neonatal illness and subsequent late intervention at the time of presentation to the hospital. ${ }^{20}$ Authors strongly believe that with further trainings and re-trainings a significant improvement in the knowledge of the whole nine signs is achievable. 
Another remarkable finding of this study is that the post-interventional phase recorded a significant improvement in the ability to seek care in a health facility for each of the newborn danger signs. The study documented significant improvement in seeking health care in a health facility for all the newborn danger signs. This is a welcome development and a landmark achievement. The symptoms of serious illness in newborns can be subtle. ${ }^{21}$ Therefore, they may elude the recognition of mothers and caregivers at home. Hence, the observed significant improvement in their ability to seek care at a health facility where healthcare workers and professionals can quickly identify these signs and institute care early enough is a welcome development that will enhance survival of the sick newborn.

The most important aspect of this care seeking is that the training has also achieved a significant improvement in the time from observing the danger signs to seeking care at a health facility. Most of the subjects now sought care at a health facility less than 24 hours after observing any danger sign in their newborn. This development will shorten level one delay (delay at household), which has been documented as a significant cause of delay in health care delivery to sick newborns and a strong contributor to neonatal mortality. ${ }^{22,23}$

\section{Conclusion}

Our study demonstrated that training of mothers can significantly enhance their knowledge of danger signs in sick newborns and improve their care-seeking behaviors. One major limitation of this study is due to its cross-sectional design and financial restrictions, we were not be able to follow these respondents through time to assess sustainability and practicality of the impacted knowledge on danger sign on the health and survival of their newborns.

\section{Declarations}

\section{Ethics approval and consent to participate}

Approval for this study was obtained from the Ethics and Research Committee of Enugu State University Teaching Hospital with approval number. TETF/DR\&D/CE/UNI/ENUGU/IBR/2019/VOL1. The research procedure was interview-based and minimally invasive. Written informed consent was obtained from the caregivers. Participants were informed that they could freely withdraw from the study at any time, even after having consented initially, and this did not in any way affect their medical care. During data collection, participants that had significant psychological condition(s) were counselled and reported to the managing team for possible referral.

\section{Consent for publication}

Not applicable

\section{Availability of data and material}


The datasets used and/or analyzed during the current study are available from the corresponding author on reasonable request.

\section{Competing interests}

The authors declare that they have no competing interests

\section{Funding}

Funding for this study was from equal contributions from all authors. No External funding was received for this study.

\section{Authors' contributions}

EU, NIK, ODIC conceptualized the study. NIK and ODIC developed and wrote the methodology. EU, NIK, $\mathrm{NOC}, \mathrm{COH}, \mathrm{AOF}, \mathrm{EC}, \mathrm{ANI}$ contributed to the introduction, result, discussion, and conclusion of the study. All authors contributed to writing and reviewed the final draft of the manuscript.

\section{Acknowledgement}

The authors would like to acknowledge the research assistants who assisted in enrolment of surveyed children from the out-patient clinic of the Enugu State University Teaching Hospital

\section{References}

1. World Health Organisation. Newborns: Improving survival and well-being. Facts sheet. Available at: https://www.who.int/news-room/fact-sheets/detail/newborns-reducingmortality\#: :text=There\%20are\%20approximately\%206\%20700,to\%202.4\%20million\%20in\%202019. Accessed on: 2/11/2021.

2. Worldbank. Data. Mortality rate, neonatal (per 1,000 live births) - Nigeria. Available at: https://data.worldbank.org/indicator/SH.DYN.NMRT? locations=NG. Accessed on 30/10/2021.

3. United Nations Children's Fund (UNICEF). Regional Office for South Asia surviving childbirth and pregnancy in south Asia.2004; 11.

4. WHO, UNICEF. Caring for the newborn at home; a training course for community health workers; community health workers manual. Geneva; 2012.

5. World Health Organization World Health Report 2005: Make Every Mother and Child Count Geneva 2005

6. Bulto GA, Fekene DB, Moti BE, Demissie GA, Daka KB. Knowledge of neonatal danger signs, care seeking practice and associated factors among postpartum mothers at public health facilities in Ambo town, Central Ethiopia. BMC Res Notes 12, 549 (2019). https://doi.org/10.1186/s13104-0194583-7 
7. Salih FA, Eltyeb EE. Neonatal mortality contributors using the three delays audit: a study from Albuluk paediatrics teaching hospital in Sudan. Int J Res Med Sci. 2017;5(12):5139-44. http://dx.doi.org/10.18203/2320-6012.ijrms20175129

8. Kananura RM, Tetui M, Mutebi A, Bua JN, Waiswa P, Kiwanuka SN, et al. The neonatal mortality and its determinants in rural communities of Eastern Uganda. Reprod Health. 2016;13(1):13. https://doi.org/10.1186/s12978-016-0119-y

9. UNICEF. Maternal and Newborn Health Disparities in Nigeria. Key Facts.

10. Ekwochi U, Ndu IK, Osuorah CD, Amadi OF, Okeke IB, Obuoha E, et al. Knowledge of danger signs in newborns and health seeking practices of mothers and care givers in Enugu state, South-East Nigeria. Ital J Pediatr. 2015 Mar 21;41:18.

11. Oyedeji GA. Socioeconomic and cultural background of hospitalized children in llesa, Nigeria. Nig J Paediatr. 1985;12:111-7.

12. Pınar Mine Güneş. The role of maternal education in child health: Evidence from a compulsory schooling law. Economics of Education Review 2015; 47:1-16

13. Valentina Di Stasio. Education as a Signal of Trainability: Results from a Vignette Study with Italian Employers European Sociological Review 2014; 30(6):796-809

14. Agbaje OS, Agu BN, Umoke PC, Ekpu FS, Orungbe NH. Child Care Practices and Associated Factors among Women of Childbearing Age Attending Health Facilities in Dekina, North-Central, Nigeria. Science. 2016 Aug 16;4(5):366-74.

15. Bick, D. E., MacArthur, C., \& Lancashire, R. J. (1998). What influences the uptake and early cessation of breastfeeding? Midwifery, 14 (4), 242-247.

16. Bayih, W.A., Birhan, B.M., Yeshambel, A. et al. Determinants of maternal knowledge of neonatal danger signs among postnatal mothers visiting neonatal intensive care unit, north Central Ethiopia, 2019: a cross-sectional study. BMC Pregnancy Childbirth 20, 218 (2020). https://doi.org/10.1186/s12884-020-02896-x

17. Kanu JS, Tang Y, Liu Y (2014) Assessment on the Knowledge and Reported Practices of Women on Maternal and Child Health in Rural Sierra Leone: A Cross-Sectional Survey. PLoS ONE 9(8): e105936. https://doi.org/10.1371/journal.pone.0105936

18. Asia KH, Rose M. Recognition of High-Risk Pregnancies and Referral Practices among Traditional Birth Attendants in Mkuranga District, Coast Region, Tanzania Asia K Hussein1 and Rose Mpembeni. Afr J Reprod Health 2005; 9[1]: 113-122) https://\&ie=utf-8\&oe=utf-8\&client=firefox-b-ab assessed 27/10/2021.

19. World Health Organization World Health Report 2005: Make Every Mother and Child Count Geneva $2005 \mathrm{https}$ :// assessed 1/10/2021

20. PeterW, KarinK, StefanP et al. Using the three delays model to understand why newborn babies die in eastern Uganda. Trop Med Int Health2010;15(8):964-72

21. Uchenna Ekwochi, Ikenna K. Ndu, Chidiebere D.I. Osuorah, Kenechi S. Onah, Ejike Obuoha, Odutola I. Odetunde, Ikenna Nwokoye, Nnenne I. Obumneme-Anyim, Ifeyinwa B. Okeke, Ogechukwu F. Amadi, 
Delays in healthcare delivery to sick neonates in Enugu South-East Nigeria: an analysis of causes and effects, Journal of Public Health, Volume 38, Issue 2, June 2016, Pages e171-e177, https://doi.org/10.1093/pubmed/fdv092 